\title{
水熱処理した木質系バイオマスの炭素化挙動
}

\author{
石橋 昇 ${ }^{* 1, * 2}$, 脇坂 博之*3, 山本 和宜 ${ }^{* 1, * 2}$, 河原 豊 ${ }^{* 1, * 4, *}$
}

\section{Carbonization Behavior of Hydrothermally Treated Woody Biomass}

\author{
Noboru Ishibashi ${ }^{* 1, * 2}$, Hiroyuki Wakizaka ${ }^{* 3}$, Kazuyoshi Yamamoto $^{* 1, * 2}$, and Yutaka Kawahara ${ }^{* 1, * 4, \#}$ \\ ${ }^{* 1}$ Department of Biological \& Chemical Engineering, Graduate School of Engineering, Gunma University, \\ 1-5-1, Tenjin-cho, Kiryu, Gunma 376-8515, Japan \\ ${ }^{* 2}$ Research Lab., Carbo-tec. Co. Ltd., 305, Creation Core Kyoto Mikuruma, \\ 448-5, Kajii, Kamigyo-ku, Kyoto 602-0841, Japan \\ ${ }^{* 3}$ North Eastern Industrial Research Center of Shiga Prefecture, \\ 27-39 Mitsuyamotomachi, Nagahama, Shiga 526-0024, Japan \\ ${ }^{*}$ The Center for Fiber \& Textile Science, Kyoto Institute of Technology, \\ Matsugasaki, Sakyo-ku, Kyoto 606-8585, Japan
}

\begin{abstract}
Influence of the hydrothermal pre-treatments on the carbonization behaviors for bark and sap wood portions of sawtooth oak wood was investigated. The shrinkage in the course of carbonization for the bark portions was promoted markedly by applying the hydrothermal pre-treatments. To the contrary as for the sap wood portions the shrinkage was suppressed. The wide-angle X-ray diffraction measurements revealed that the hydrothermal treatments also affected the formation of the carbon layer stacking. The hydrothermal pre-treatments seem to have some potential to control the shrinkage and the formation of carbon crystallites in the production of charcoal from woody biomass.
\end{abstract}

(Received 23 July, 2012; Accepted 4 September, 2012)

\section{1. 緒 言}

燃料としての木炭の生産は, 昭和 30 年代の燃料革命に よって大きく衰退したが，木炭を用いる文化の中で「茶 の湯」は京都を中心に引き継がれ，「茶の湯炭」として今 日においても，国内で伝統的に生産されている。この「茶 の湯炭」の生産にはクヌギ(Quercus acutissima Carruth.) が 使用されるが, 高級な「茶の湯炭」は, 製炭後, 樹皮と 辺材が形成層の位置で剥離することなく, かつ, 木材の 横断面(木口面)を切り出したとき, 道管の配列に打いて 䯣(樹心)から放射状の配列をとるクヌギでは, クラック が放射孔に沿って進展していることが要求される。この 様なクラックを複数もつ木口面は, まるで菊の家紋の様 に見えるため「菊炭」といわれる [1].

この特殊な木炭を生産技術面から捉えたとき，まず， 熱分解しながら炭素化・収縮する樹皮と辺材が形成層の

\# corresponding author

*1 群馬大学大学院工学研究科

*2 株式会社カーボテック

*3 滋賀県東北部工業技術センター

*4 京都工芸繊維大学繊維科学センター
位置で剥離しないようにすることが重要な課題となるが, 両者の生体組織構造は全く異なるため, また, 化学組成 に执いてもセルロース系多糖とリグニンの構成比率(リグ ノセルロース構造)が異なり, 単純に炭素化すると樹皮の 脱落・崩壊が生じる.

リグノセルロース構造は全く異なるが, 著者の一人は これまでケナフについて水熱処理を検討し，この処理が LCC (Lignin carbohydrate complex)を部分的に破壊してリグ ニンの溶出分離に有効であることを確認している $[2]$. そ こで, 本研究では, クヌギの樹皮, 辺材に水熱処理を行っ てリグニン成分を減少させたときの炭素化収縮率や炭素 構造パラメー夕の変化を調べ, 樹皮の剝れを防止して「菊 炭」の生産歩留まりを向上するための前処理として, 水 熱処理の可能性について検討した.

\section{2. 実 験}

\section{1 試料}

春先, 2010 年 3 月 9 日に, 京都府亀岡市周辺地域の山 林から伐採して自然乾燥したクヌギを用いた。䯣を含み 厚さ約 $5 \mathrm{~mm}$ の柾目板になるよう試料を切り出して, 形成 層の位置で樹皮 (bark) と辺材 (sap wood)を分離して用いた。 


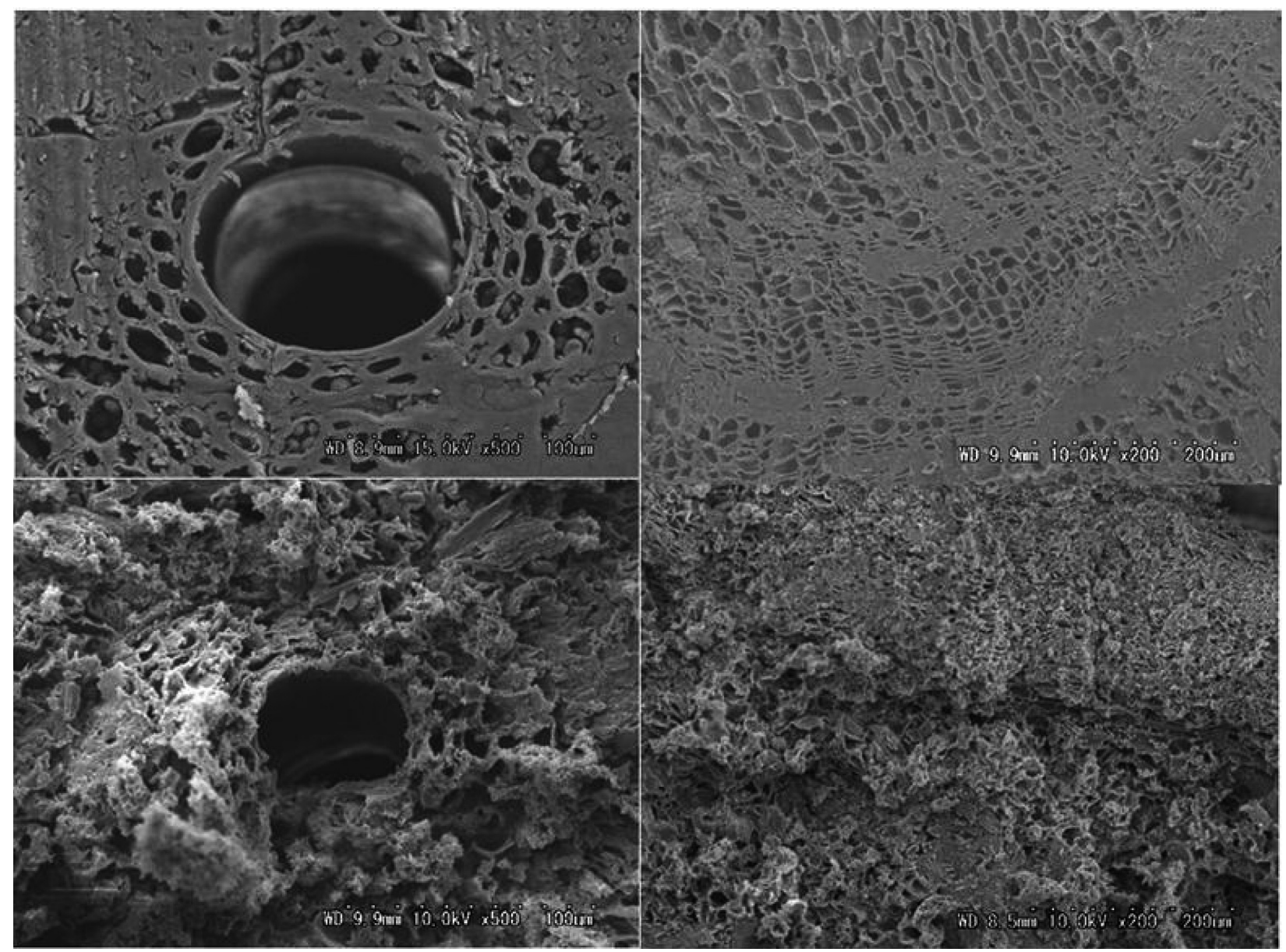

Fig. 1 Scanning electron micrographs for the cross section of sap wood (top left) and the bark (top right) of sawtooth oak wood, and hydrothermally treated (each bottom).
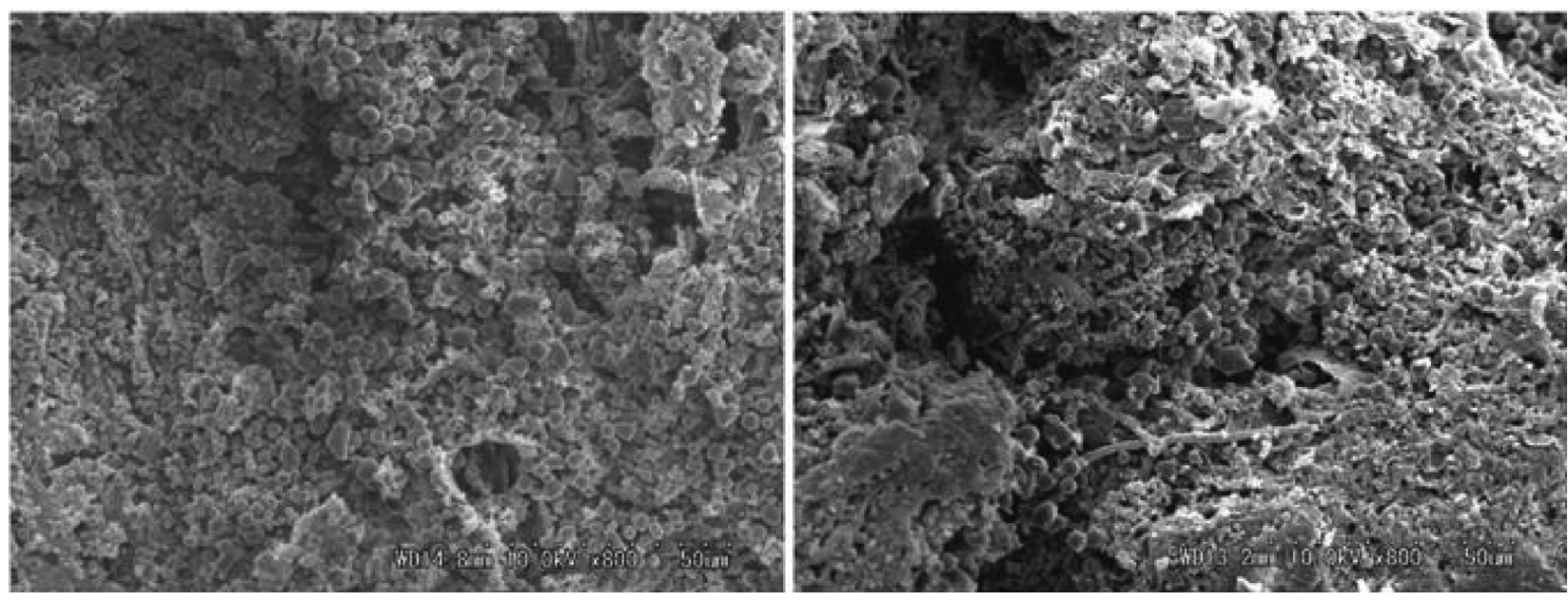

Fig. 2 Scanning electron micrographs for the surface of hydrothermally treated sap wood (left) and bark (right) of sawtooth oak wood. 
試験片大きさは, 水熱反応容器の内容積の関係で $11 \mathrm{~mm}$ (幅: 木の放射方向 $) \times 5 \mathrm{~mm}$ (厚 : 接線方向 $) \times 65 \mathrm{~mm}$ (長さ : 成 長方向)とした.

\section{2 水熱処理及び水蒸気処理}

ステンレス容器(容積 $50 \mathrm{ml}$ ) に浴比約 $1: 18$ で試験片を 水漬状態にして $180 \sim 200^{\circ} \mathrm{C}$ で $2 \mathrm{~h}$ 処理する方法(水熱処 理) と, 容器に水 $7 \mathrm{ml}$ を入れた後, 試験片をステンレスメッ シュに載せ, 試験片に水が接触しないようにして 180 $200{ }^{\circ} \mathrm{C}$ の高温水蒸気に $2 \mathrm{~h}$ 暴露する処理方法 (水蒸気処理) を用いた. 各熱処理における昇温速度は $10^{\circ} \mathrm{C} / \mathrm{min}$ とした.

\section{3 炭素化処理}

炭素化は, 試験片を磁製血に載せ管状炭化炉(直径 $32 \mathrm{~mm}$, 長さ $300 \mathrm{~mm}$, 均熱帯約 $60 \mathrm{~mm}$ ) に入れ, 窒素雾囲 気下 $(0.5 \mathrm{~L} / \mathrm{min})$ にて昇温速度 $10^{\circ} \mathrm{C} / \mathrm{min}$, 処理温度 $800^{\circ} \mathrm{C}$ で $15 \mathrm{~min}$ 保持することで行った。

\section{4 測 定}

水熱処理後の表面について走査型電子顕微鏡 $(\mathrm{SEM})$ 観 察を行い $(\mathrm{S}-3000 \mathrm{~N}$, 日立製), 処理液については, $\mathrm{pH}$, 紫 外吸収スペクトル (UV, V-550, 日本分光)の測定を行っ た.また，炭素化による収縮率測定，熱重量分析 (TG/DTA WS-002, ブルカーエイエックスエス)を用いた炭素化過程 の評価 $\left(\mathrm{N}_{2}\right.$ 䨌囲気: 流量 $50 \mathrm{ml} / \mathrm{min}$, 昇温速度 $\left.20^{\circ} \mathrm{C} / \mathrm{min}\right)$ と, 生成した炭素の結晶構造を 002 回折強度曲線から Hirsch 法[3-5]を用いて, 市販ソフトウエア (Carbon Analyzer, Ver. 4.00, 菱化システム製)により, 平均網面間距離, 平 均積層枚数, 平均微結晶サイズを評価した.

\section{3. 結果と考察}

\section{1 リグノセルロース構造の変化}

クヌギの樹皮の断面および辺材(木口面)の水熱処理 $\left(180^{\circ} \mathrm{C}\right)$ 後の形態を SEM 観察したところ, セル構造がや や浮き上がって変形したことがわかる(図 1). また, $5 \mu \mathrm{m}$ 未満の微小粒状物の析出がいずれの部位においても認め られた (図 2). 同様な粒状物の析出をケナフにおいても確 認している[2]. GC/MS を用いて検討したところ, ケナ フの場合, 主成分は油分あるいはリグニンの一部と推測 された [6]. 一方, 水熱処理後の残液について UV スペク トルを測定したところ，200nm と $280 \mathrm{~nm}$ にリグニンに特 徵的なエチレンバンド及びベンゾイドバンドの吸収ピー クが確認され[7], ジュート繊維と同様にリグノセルロー ス構造が破壊されリグニンが溶出していることがわかっ た $[8]$. 水熱処理による重量減少率を調べたところ樹皮で $25.6 \%$, 辺材で $18.2 \%$ であた. また, 未処理の試料につ いてリグニン含有量を酸不溶性リグニンから評価[9]した

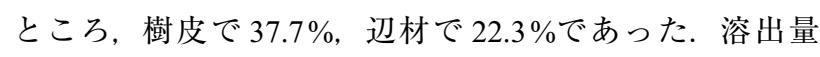
との関連が考えられる.

処理後の残液 (未希釈)について, $\mathrm{pH}$ を水熱処理と水蒸 気処理で比較したところ, 前者では 3.5 であったが, 後者 では 3.0 となった。一般に動物ほど厳密ではないが植物の
樹液の $\mathrm{pH}$ は, 4.0〜6.2 の範囲に維持されている [11-12]. ちなみにスギの場合, 木質部の $\mathrm{p} K_{\mathrm{a}}$ は 6.05 程度である $[13]$. $\mathrm{pH}$ の低下は水熱処理によってへミセルロースやリグニン の一部が分解して酢酸, ギ酸が生成したためと考えられ る $[10]$. 水蒸気処理の方が, 若干, $\mathrm{pH}$ の低下が大きくなっ ているが, 残液の量が水熱処理の約 $1 / 3$ であったため, 見 掛け $\mathrm{pH}$ が低下した. 実験範囲内で処理方法による有機酸 の溶出量の違いは殆どないと考えられる.

\section{2 炭素化挙動}

図 3 に窒素䨌囲気下で測定した TG/DTA 曲線を示す. 樹皮の方が含水率が高いため, 昇温開始から水の蒸発に よる重量減少が顕著に認められ, $80^{\circ} \mathrm{C} に$ 吸熱ピークを生 じた。熱分解は，いずれの部位でも $250^{\circ} \mathrm{Cを}$ 過ぎると著 しくなり, $400{ }^{\circ} \mathrm{C}$ でほほ終了し, $500{ }^{\circ} \mathrm{C}$ で同程度の炭素化

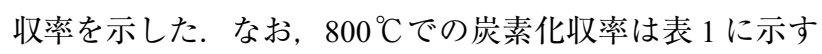
通り，樹皮 $31.0 \%$, 辺材 $25.2 \%$ となった。

これまでの経験で，木炭を製造したときの樹皮の剥離
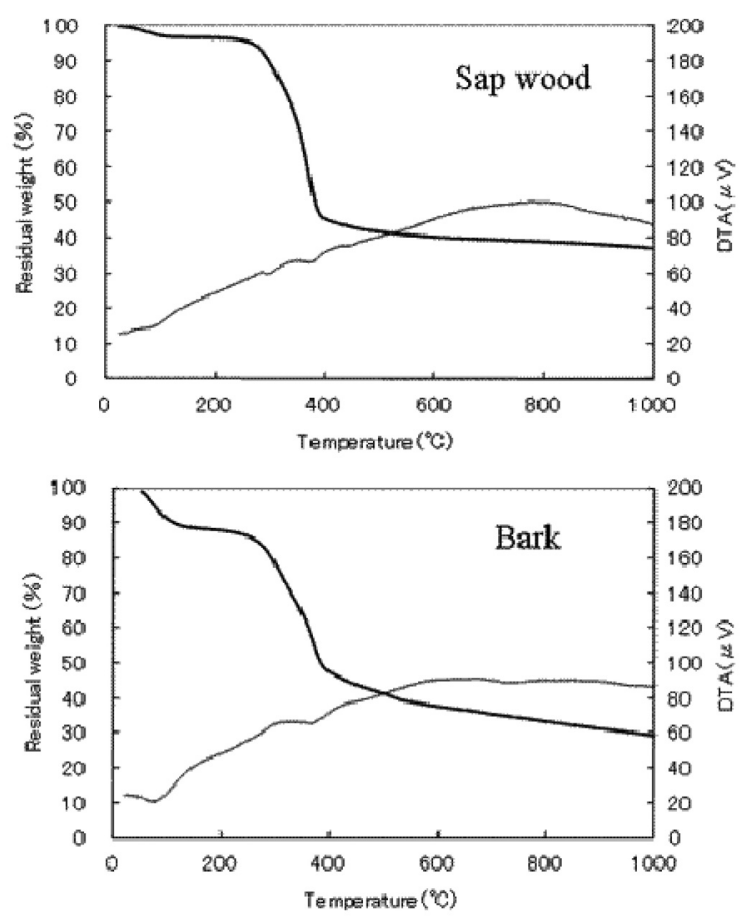

Fig. 3 TG/DTA curves for sap wood and bark portions of sawtooth oak wood measured under $\mathrm{N}_{2}$ gas flow : bold, TG ; fine, DTA.

Table 1 Influence of hydrothermal treatments on the carbonization behaviors of sawtooth oak.

\begin{tabular}{llllll}
\hline Sample & $\begin{array}{l}\text { Hydro- } \\
\text { thermal } \\
\text { treatment }\end{array}$ & $\begin{array}{l}\text { Carbon } \\
\text { yield at } \\
800{ }^{\circ} \mathrm{C} \\
(\%)\end{array}$ & \multicolumn{4}{c}{ Shrinkage (\%) } \\
\hline Sap & Untreated & 25.2 & 29.8 & 33.6 & 53.4 \\
wood & Water $\left(180^{\circ} \mathrm{C}\right)$ & 21.6 & 23.7 & 36.7 & 51.7 \\
\hline \multirow{3}{*}{ Bark } & Untreated & 31.0 & 20.9 & 18.5 & 35.5 \\
& Water $\left(180^{\circ} \mathrm{C}\right)$ & 33.1 & 20.8 & 21.9 & 38.1 \\
& Steam $\left(200^{\circ} \mathrm{C}\right)$ & 39.7 & 21.7 & 22.3 & 39.2 \\
\hline
\end{tabular}


Table 2 Structural parameters for the carbon crystallites in the charcoal.

\begin{tabular}{llccc}
\hline Sample & $\begin{array}{l}\text { Hydro- } \\
\text { thermal } \\
\text { treatment }\end{array}$ & $\begin{array}{l}\text { Interlayer } \\
\text { spacing, } \\
d_{002} \\
(\mathrm{~nm})\end{array}$ & $\begin{array}{l}\text { Number } \\
\text { of carbon } \\
\text { layers }\end{array}$ & $\begin{array}{l}\text { Average carbon } \\
\text { layer stack } \\
\text { height, } L c \\
(\mathrm{~nm})\end{array}$ \\
\hline Sap & Untreated & 0.39 & 2.6 & 0.63 \\
wood & Water $\left(180^{\circ} \mathrm{C}\right)$ & 0.36 & 2.2 & 0.45 \\
\hline \multirow{3}{*}{ Bark } & Untreated & 0.33 & 2.4 & 0.46 \\
& Water $\left(180^{\circ} \mathrm{C}\right)$ & 0.30 & 2.9 & 0.58 \\
& Steam $\left(200^{\circ} \mathrm{C}\right)$ & 0.34 & 2.2 & 0.43 \\
\hline
\end{tabular}

は, 樹皮の接線方向(周方向)の炭素化収縮に比べて辺材 の放射方向(半径方向)の収縮が大き過ぎるため，つまり， 辺材が細化し過ぎるために生じていることを確認してい る，そこで，まず，炭素化後の収縮率を調べた。表 1 に 結果を示す。辺材を水熱処理 $\left(180^{\circ} \mathrm{C}\right)$ すると, 炭素収率 $\left(800^{\circ} \mathrm{C}\right)$ がやや低下して木口面の面積収縮率も若干減少し た. 一方, 樹皮では水熱処理すると炭素収率が増加し, 面積収縮率も増大した. この傾向は, より高温の水蒸気 処理によってさらに顕著になった. 水熱処理によってリ グニンが溶出し, リグノセルロース構造に何らかの変化 が生じていることは, pHの変化や UV スペクトルから確 認したが, このことが, 結果的に両組織の炭素化挙動に おいて相反する効果となって反映されている。 なお，今 回の水蒸気処理の範囲では, 辺材の炭素化による収縮は, 樹皮に比べて依然として大きく, 実際に「菊炭」の生産 歩留まりを向上させるためには, より長時間の水蒸気処 理を樹皮に行う必要があると推測される.

水熱処理による炭素構造への影響を樹皮と辺材で比較 した．表 2 に結果を示す。樹皮の水蒸気処理 $\left(200{ }^{\circ} \mathrm{C}\right)$ では, 未処理と同様な炭素構造であることが分かった。一方, 水熱処理 $\left(180^{\circ} \mathrm{C}\right)$ した場合, 辺材では $L c$ が $0.63 \rightarrow 0.45$ と 低下して炭素化がやや阻害され, 樹皮では $L c$ が $0.46 \rightarrow 0.58$ と増加して促進されることがわかった．今後，より詳細 に検討する必要がある.

\section{4. 結 言}

水熱反応の工業分野への応用として，「菊炭」の生産歩 留まりの向上の可能性を検討した，炭素化収縮を制御し て樹皮の剥離を防止する手段として，まだまだ不十分で はあるが, 少なくとも炭素化の前処理として高温水蒸気 に樹皮を暴露することは，有効であることが示唆された．

\section{謝 辞}

本研究は, 平成 21 年度京都府緊急雇用対策事業, 「国 産茶の湯炭復興事業」の一部として行われたものであり, 深謝申し上げます。

\section{文 献}

1. S. Kishimoto, "A complete of charcoal", Soshinsya Co. Ltd., Tokyo, p.49 (1998).

2. H. Minami, S. Nishiuchi, J. Kadono, Y. Sugimura, and Y. Kawahara, Sen'i Gakkaishi, 65, 338(2009).

3. P. B. Hirsch, Proc. Roy. Soc., A226, 143 (1954).

4. W. Ruland, Carbon, 2, 365 (1965).

5. H. Fujimoto, and M. Shiraishi, TANSO, 213, 123 (2004).

6. H. Minami, J. Kadono, S. Nishiuchi, Y. Sugimura, and Y. Kawahara, Sen'i Gakkaishi, submitted.

7. N.Terashima, "Lignin no Kagaku” (J. Nakano, Ed.), Unishuppan, Tokyo, p.169 (1990).

8. Y.Kawahara, Y.Kawata, R.Endo, H.Minami and S. Nishiuchi, Sen'i Gakkaishi, 61, 142 (2005).

9. "Mokushitsu Kagaku Zikken Manual”, (Nihon Mokuzaigakkai, Ed.), Buneido Publishing Co. Ltd., Tokyo, p.92 (2000).

10. H.Abe, "Mokuzai Kogyo Handbook”, Maruzen, Tokyo, p.145 (1982).

11. D.D.Perrin, and B.Dempsey, "Buffers for $p H$ and metal ion control", Chapman and Hall, London (1974).

12. K.Tsuji, "Kansyoueki no sentaku to ohyou", Kodansha Scientific Co., Tokyo, pp.3-9 (1984).

13. H.Ohashi, S.Yokota, and M.Yasue, Res. Bul. Fac. Agr. Gifu Univ., 50, 145 (1985). 